\title{
Cost of Care
}

\section{Medical Expenditures during the Last Year of Life: Findings from the 1992-1996 Medicare Current Beneficiary Survey}

\author{
Donald R. Hoover, Stephen Crystal, Rizie Kumar, \\ Usha Sambamoorthi, and Joel C. Cantor
}

Objective. To compare medical expenditures for the elderly (65 years old) over the last year of life with those for nonterminal years.

Data Source. From the 1992-1996 Medicare Current Beneficiary Survey (MCBS) data from about ten thousand elderly persons each year.

Study Design. Medical expenditures for the last year of life and nonterminal years by source of payment and type of care were estimated using robust covariance linear model approaches applied to MCBS data.

Data Collection. The MCBS is a panel survey of a complex weighted multilevel random sample of Medicare beneficiaries. A structured questionnaire is administered at four-month intervals to collect all medical costs by payer and service. Medicare costs are validated by claims records.

Principal Findings. From 1992 to 1996, mean annual medical expenditures (1996 dollars) for persons aged 65 and older were $\$ 37,581$ during the last year of life versus $\$ 7,365$ for nonterminal years. Mean total last-year-of-life expenditures did not differ greatly by age at death. However, non-Medicare last-year-of-life expenditures were higher and Medicare last-year-of-life expenditures were lower for those dying at older ages. Last-year-of-life expenses constituted 22 percent of all medical, 26 percent of Medicare, 18 percent of all non-Medicare expenditures, and 25 percent of Medicaid expenditures.

Conclusions. While health services delivered near the end of life will continue to consume large portions of medical dollars, the portion paid by non-Medicare sources will likely rise as the population ages. Policies promoting improved allocation of resources for end-of-life care may not affect non-Medicare expenditures, which disproportionately support chronic and custodial care.

Key Words. End of life, elderly, health care expenditures, Medicare, Medicaid

The elderly (65 years of age and older) have consumed more than 33 percent of health care spending (Waldo, Sonnefeld, and Arnett 1989). Their medical expenses are substantially higher in the last year of life (Scitovsky 1984; Riley 
et al. 1987; Scitovsky 1988; Gaumer and Stavins 1992; Temkin-Greener et al. 1992; Lubitz and Riley 1993; Scitovsky 1994; Barnato et al. 1999). While only 5 percent of elderly Medicare beneficiaries have died annually, the percentage of elderly Medicare expenditures spent on persons in the last year of life fluctuates between 27 percent and 31 percent (Lubitz and Riley 1993; Hogan et al. 2001). Mean annual Medicare expenditures for the last 12 months of life in the elderly rose from $\$ 1,924$ in 1976 to about $\$ 23,000$ in 1995 , but the portion of Medicare expenditures spent on beneficiaries in the last year of life did not change during this time period (Lubitz and Riley 1993; Garber, MaCurdy, and McClellan 1999; Hogan et al 2001).

Inpatient hospital expenditures constitute a large portion of end-of-life expenses, but use of this service by terminally ill patients declined in the late 1980s and early 1990s (Temkin-Greener et al. 1992; Lubitz and Riley 1993; Scitovsky 1994; Garber MaCurdy, and McClellan 1999). Still, Garber et al. (1999) observed that hospital inpatient Medicare expenditures in the last year of life among the 20 percent Medicare sample grew from 1989-1995, although perhaps not as rapidly as did expenditures for other services during this time period. Recent initiatives to promote the use of home health care, hospice, and advanced directives might be expected to curtail "unnecessary" or unwanted inpatient hospital and other end-of-life services, but these services are difficult to target without also reducing valuable services (Emanuel and Emanuel 1994).

The continuing growth of population in the oldest age groups in the United States could also change the portion of medical expenditures spent on the last year of life either through larger numbers of elderly deaths or different medical spending patterns for those dying at the oldest ages. Medicare expenditures during the last 12 months of life decline with age at death (McCall 1984; Scitovsky 1984; Lubitz and Riley 1993). Reasons suggested for

This research was supported by grants 1 R03HS09566 and 1P20HS11825 from AHRQ, and by 1 R03 AG 15166 and R01 MH 60831 from NIH and was presented on November 14, 2000, at the 128th American Public Health Association Meeting in Boston, Massachusetts. The findings and opinions reported here are those of the authors and do not necessarily represent the views of any other individuals or organizations.

Address correspondence to Dr. Donald Hoover, Ph.D., M.P.H., Department of Statistics, Rutgers University, 473 Hill Center, 110 Frelinghuysen Road, Piscataway, New Jersey 08854-8019. He is also with the Institute for Health, Health Care Policy and Aging Research, Rutgers University, New Brunswick, New Jersey. Stephen Crystal, Ph.D., Rizie Kumar, M.S., Usha Sambamoorthi, Ph.D., and Joel C. Cantor, Sc.D., are with the Institute for Health, Health Care Policy and Aging Research at Rutgers as well. 
this include shorter intervals between illness and death and decreased use of acute care, hospitals, and other services with older age at death (Gaumer and Stavins 1992; Scitovsky 1994), as well as less desire among the oldest individuals or their health care providers to use advanced (and expensive) technological methods to prolong their lives (Kramer 1995). By contrast, endof-life non-Medicare expenses are higher among those with older age at death. Three studies observed rising non-Medicare expenditures with older age at death during the last 90 days of life (Temkin-Greener et al. 1992), last year of life (Scitovsky 1984), and last two years of life (Spillman and Lubitz 2000). This increase in terminal year non-Medicare expenditures with older age at death was largely from greater long-term care facility expenditures for older decedents.

Evaluating Medicare and non-Medicare expenditures among the elderly near the end of life remains important as the American population ages. But end-of-life non-Medicare and total elderly medical expenditures have not been studied or compared to non-end-of-life expenditures in a national sample. We, therefore, study 1992-1996 Medicare and nonMedicare expenditures during the last 12 months of life (referred to as "terminal year expenditures") as compared to expenditures before the last 12 months of life (referred to as "nonterminal year expenditures") using data from the Medicare Beneficiary Survey (MCBS). Expenses are subdivided according to service, payer, and person's age. Implications of the findings with respect to current and future health care costs and efforts to reduce medical expenditures are discussed.

\section{METHODS}

\section{Study Population and Expenditure Data}

The 1992-1996 MCBS is a weighted, stratified, multistage, area probability sample of Medicare enrollees (community and facility dwellers) drawn from the Medicare enrollment file maintained by the Health Care Financing Administration (HCFA). This sample is supplemented annually to add newly enrolled individuals and replace attrition from death. The MCBS interviews participants/proxies every four months, reviewing all health care encounters with the assistance of calendars, along with explanation of benefits from all payers. To improve accuracy of data, respondents record medical events/ procedures on special calendars, and bring receipts, statements, and medication containers to the interview. In computing Medicare expenditures, 
MCBS cross-checks and supplements the survey with Medicare claims information. For facility residents, billing office workers are asked to provide data on charges and payments. However, only total health care expenditures for a calendar year (or the portion of the year a person survives) are recorded and non-Medicare costs cannot be subdivided further from available information on dates of service. More details on the MCBS are given elsewhere (Olin, Liu, and Merriman 1996; Eppig and Chulis 1997). This analysis includes full-year Medicare enrollees aged 65 and older on January 1 of the MCBS calendar year.

\section{Measures of Medical Expenditures}

The MCBS divides medical expenses by payer source and service. We analyzed the following expense categories:

- All Medical Expenses: All medical payments from the payers described below.

- Medicare: Paid by Medicare including those by Medicare-funded health maintenance organizations (HMOs).

- Non-Medicare: Medical expenses not paid by Medicare.

The following major non-Medicare sources were analyzed separately:

- Out-of-pocket: Includes copayments, deductibles, balance billing payments to physicians, and payments made directly by family members or other persons for the respondent.

- Medicaid: Includes copayments to Medicare and deductibles.

- Insurance: Payments by nonpublic insurers including employer-paid coverage and Medicare supplement policies.

Payments made by the Veterans Administration and local health programs and expenditures discounted by the provider were included in the total, but not analyzed separately. Payments by HMOs (both Medicare- and non-Medicare-funded HMOs combined) were also analyzed as a separate category.

Expenditures were analyzed separately by service category: inpatient hospital, outpatient hospital, prescription drugs (excluding inpatient/facility prescribed medications which were included in those categories), medical provider (payments made to physicians and other clinicians providing patient care), home health care, dental services, hospice, and facility (licensed/skilled nursing homes, intermediate care facilities, retirement homes, domiciliary 
facilities, hospital long-term care units, assisted/foster care homes and mental health/developmentally disabled care facilities). Short term stays (when admission and discharge are in the same year) in long-term care facilities were noted in a separate category: institutional events.

\section{Statistical Models and Analysis}

We define terminal year expenditures as those for persons who died 12 or fewer months after the expense date and nonterminal year expenditures as all other expenses. The statistical challenge to estimate terminal year (last 12 months of life) and nonterminal year expenses is that MCBS expenditures are recorded for an entire calendar year rather than on a daily (or monthly) basis. We only observe expenses over the entire calendar year (or portion the person was alive) rather than directly observing expenses for a person's last 12 months of life. For example, consider 1996 MCBS costs for two persons: one dying on July 1, 1996, and one dying on July 1, 1997. For the person dying on July 1 , 1996, the 1996 MCBS would have expenses only for the last 6 months of life that occurred in 1996, while those occurring 7-12 months prior to death are in 1995 and thus unavailable. For the person dying on July 1, 1997, then the MCBS data would inseparably lump expenses occurring 7-12 months prior to death (the part of the person's terminal year of life that was in 1996) together with those occurring 13-18 months prior to death (which also occurred in 1996 but was not during the person's last year of life).

Mean expenditures during last 1, 3, 6, and 12 months of life were thus modeled, using data from those dying in the given MCBS calendar year, with robust covariance linear polynomial models starting with four terms: $E=a+b_{1} \sqrt{m}+b_{2} m+b_{3} m^{2}$, where $E$ is the expense of interest and $m$ is the exact month of death including fractions of months. To prevent overparameterization, the least significant terms were removed by backward selection until all terms were significant at $p<0.05$. To prevent underparameterization, removal of terms stopped when a model was reduced to two terms. These models were fit for all participants and separate models were fit for three age categories (65-74, 75-84, and 85+ years). From the coefficient estimates, their covariances, and Cramer's theorem (Lehman 1997), point estimates with 95 percent confidence limits for portions of terminal year expenses occurring in the last $m=1,3$, and 6 months of life were obtained. Lubitz and Riley (1993) used a similar approach with the 5 percent Medicare sample. 
From estimates of: (1) Mean $E$ for last 12 months of life; (2) overall mean calendar year $E$ for all subjects (those who did and did not die during that year); (3) mean portion of the sample dying annually; and (4) the variances (and covariances) of these estimates, we obtained point estimates and confidence limits for: (a) Total (annual) expenses directed to terminal and nonterminal years; (b) mean annual $E$ for nonterminal years; (c) percent of all expenditures spent for terminal years; and (d) ratio (mean expenses during terminal year/mean annual expenses during nonterminal years). Briefly, equations for the quantities given in a, b, c, and d above based on the terms given in 1, 2, and 3 above were derived. Then, point estimates of the terms in 1, 2, and 3 obtained from the MCBS data and previously described linear models were input into these equations to obtain point estimates for the quantities a, b, c, and d. Incorporation of estimable covariances in 4 (conservatively setting inestimable covariances to zero) then produced conservative 95 percent confidence limits for the quantities in a-d via Cramer's theorem.

Point estimates for the portion of total terminal year expenditures for each payer (and service) were obtained as the ratio $U / V$, where $U$ is the estimated terminal year mean for expenditure of interest and $V$ the estimated terminal year mean for all medical expenditures (estimates for $U$ and $V$ were obtained from the previously described polynomial linear regression models). Application of Cramer's theorem with the variances of estimated $U$ and $V$ (conservatively setting covariance of these terms to zero) produced 95 percent confidence intervals. A similar approach (using estimates from b) obtained with confidence limits the portion of total nonterminal year expenditures for each payer (or service) category.

The full details of the approaches taken to estimate terminal year and nonterminal year expenditures from these data are in a Technical Appendix that is available upon request from the first author. All analyses accounted for the probability of participant selection into the MCBS and intracluster correlation (including correlation of measures from the same individuals in different calendar years). SUDAAN(Shah, Barnwell, and Bieler 1996) models using sample weights, Taylor linearization at primary sampling unit, and subpopulation statements were fit. As has been done previously (Lubitz and Riley 1993), to account for temporal changes in medical expenditures that exceeded inflation, expenditures were indexed to 1996 through multiplication by mean 1996 expenses divided by mean medical expenses for the given expenditure calendar year $(1992,1993,1994$, or 1995). It should be noted that direct interpretation and, in particular, temporal comparison of costs adjusted 
in this manner is complicated by the inability to factor in potential changes in quality of service over time (Cutler and McClellan 2001).

\section{RESULTS}

\section{Summary of the Sample}

Our sample consisted of 49,505 person-calendar years, and 6.5 percent of the MCBS participants (5.2 percent after adjusting for sampling weights) died during a calendar year of observation. From this point on, all means and fractions reported here are adjusted for sampling weights. Slightly more than half the participants were 65-74 years old on January 1 of the MCBS year, with about 35 percent and 10 percent, respectively, being 75-84 years old and $85+$, respectively. Table 1 presents MCBS “current dollar" measures of medical expenses (expenditures in years 1992-1995 not yet adjusted to 1996) and death rates by calendar year.

Mean total (current-dollar) medical expenditures rose in all categories from 1992-1996; for example, the mean of all medical expenditures per person-calendar year rose from $\$ 6,634$ in 1992 to $\$ 8,742$ in 1996 . The proportions of individuals with any expense in a given category are shown in parentheses and mostly did not change or rose slightly from 1992-1996. However, the proportion of subjects for whom expenditures were made by HMOs (Medicare and/or non-Medicare) increased from 10 percent in 1992 to 18 percent in $1996(p<0.001)$.

\section{Estimates of Terminal Year and Nonterminal Year Expenditures}

Table 2 presents, by category, estimated mean expenditures during the last year (12 months) of life (terminal year) and mean annual (12-month) expenditures occurring prior to the last year of life (nonterminal years). From this point on, 1992-1995 expenses are indexed to 1996 dollars as described in the methods section.

The mean for all expenditures (in 1996 dollars) during the terminal year was $\$ 37,581$, consisting of \$23,739 in Medicare and \$13,842 in non-Medicare expenditures. When broken down by age (at January 1 of last calendar year of life), 65-74- and 75-84-year-olds had mean last-year-of-life Medicare expenditures of $\$ 27,832$ and $\$ 26,078$, respectively. These were significantly higher (noted by 95 percent confidence intervals) than mean terminal year Medicare expenditures of $\$ 18,226$ for $85+$ persons. The opposite trend was seen for terminal year non-Medicare expenditures with means of $\$ 9,211$ for 


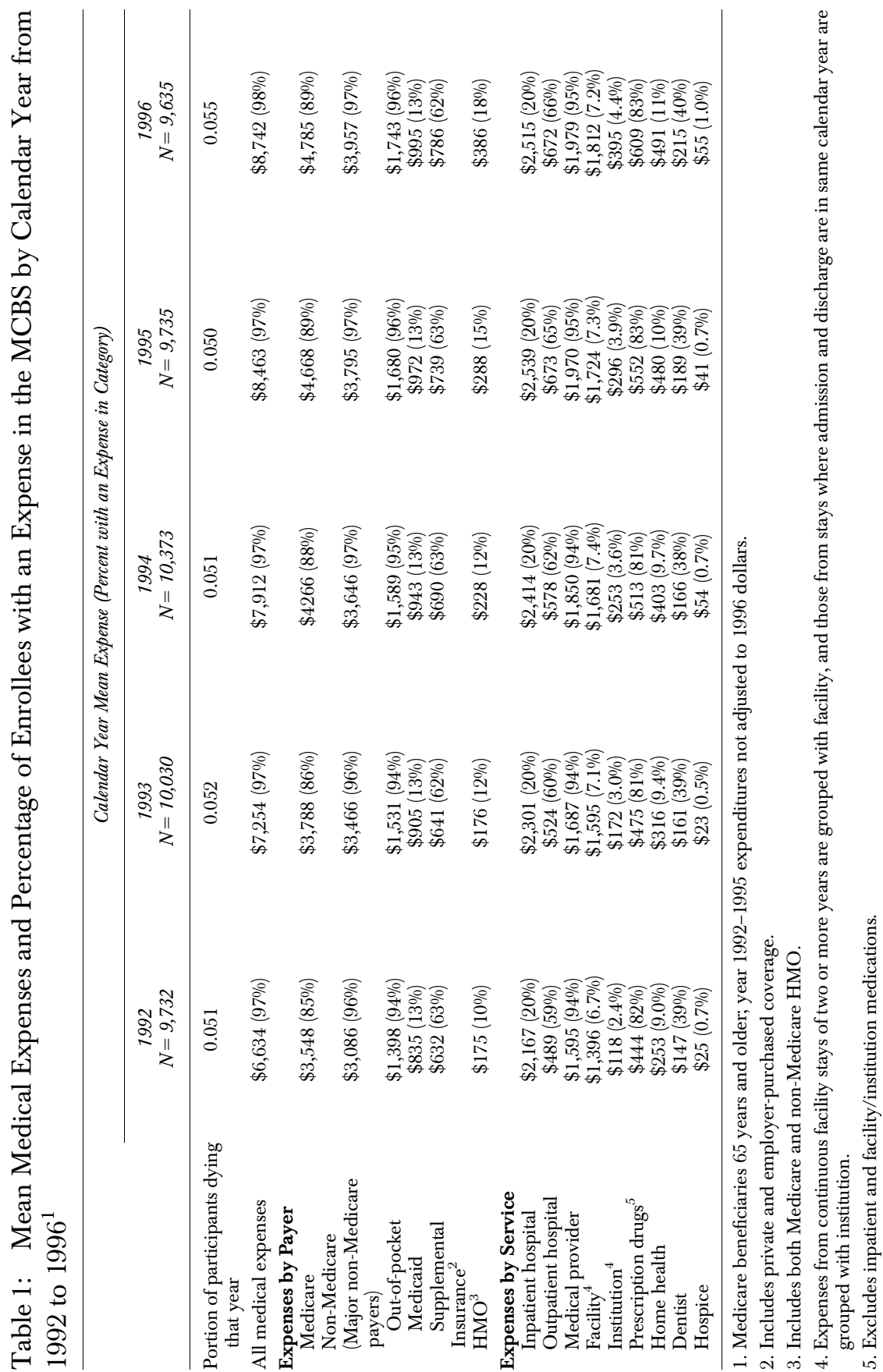


Table 2: Means of Medical Expenses for Terminal Year and Nonterminal Year from 1992 to $1996^{1}$

\begin{tabular}{|c|c|c|}
\hline Expense Category & $\begin{array}{c}\text { Terminal Year Mean } \\
\text { Last-Year-of-Life } \\
\text { Cost in 1996 Dollars } \\
\text { (95\% CI) }\end{array}$ & $\begin{array}{c}\text { Nonterminal Year } \\
\text { Mean Annual Cost in } \\
1996 \text { Dollars (95\% CI) }\end{array}$ \\
\hline 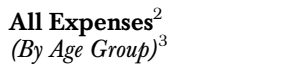 & $37,581(35,119-40,214)$ & $7,365(6,912-7,847)$ \\
\hline $65-74$ & $37,043(32,499-42,222)$ & $5,719(5,285-6,190)$ \\
\hline $75-84$ & $38,529(35,138-42,249)$ & $7,832(7,192-8,530)$ \\
\hline $85+$ & $36,985(33,827-40,361)$ & $13,895(12,660-15,250)$ \\
\hline \multicolumn{3}{|l|}{ Expenses by Payer } \\
\hline (By Age Group) $)^{3}$ & $23,739(20,905-26,957)$ & $3,775(3,436-4,147)$ \\
\hline $65-74$ & $27,832(23,668-32,730)$ & $3,247(2,913-3,618)$ \\
\hline $75-84$ & $26,078(23,977-28,365)$ & $4,153(3,776-4,567)$ \\
\hline $85+$ & $18,226(16,385-20,273)$ & $5,052(4,373-5,837)$ \\
\hline \multicolumn{3}{|l|}{ Non-Medicare } \\
\hline (By Age Group) $)^{3}$ & $13,842(12,703-15,083)$ & $3,590(3,364-3,830)$ \\
\hline $65-74$ & $9,211(6,938-12,228)$ & $2,472(2,286-2,673)$ \\
\hline $75-84$ & $12,451(11,028-14,058)$ & $3,679(3,406-3,974)$ \\
\hline $85+$ & $18,689(16,436-21,252)$ & $8,843(7,911-9,884)$ \\
\hline \multicolumn{3}{|l|}{ (Major Payers) } \\
\hline Out-of- pocket & $5,211(4,753-5,714)$ & $1,641(1,541-1,747)$ \\
\hline Medicaid & $5,051(4,331-5,891)$ & $849(723-999)$ \\
\hline Supplemental insurance ${ }^{4}$ & $2,097(1,590-2,763)$ & $731(668-800)$ \\
\hline $\mathrm{HMO}^{5}$ & $641(393-1045)$ & $264(180-387)$ \\
\hline \multicolumn{3}{|l|}{ Expenses by Service $^{6}$} \\
\hline Inpatient care & $15,461(13,891-17,209)$ & $2,040(1,816-2,293)$ \\
\hline Outpatient hospital & $1,846(1,457-2,338)$ & $608(558-662)$ \\
\hline Medical provider & $6,377(5,808-7,002)$ & $1,851(1,735-1,975)$ \\
\hline Facility $^{7^{1}}$ & $8,879(7,882-10,004)$ & $1,497(1,313-1,708)$ \\
\hline Institution $^{7}$ & $2,227(1,849-2,682)$ & $167(131-213)$ \\
\hline Prescription drugs ${ }^{8}$ & $653(588-724)$ & $593(575-612)$ \\
\hline Home health & $1,854(1,602-2,147)$ & $362(309-424)$ \\
\hline Dental & $93(55-158)$ & $207(186-232)$ \\
\hline Hospice & $735(530-1,119)$ & $6^{9}$ \\
\hline
\end{tabular}

1. Medicare beneficiaries 65 years of age and older; year 1992-1995 expenditures adjusted to 1996 dollars.

2. Adjusted to be consistent with sum of Medicare and non-Medicare expenses.

3. Age on January 1 of terminal year or nonterminal year.

4. Includes private and employer-purchased coverage.

5. Includes both Medicare and non-Medicare HMO.

6. Sums of means (in columns 2 and 3 ) for services are slightly different than the means for all expenses due to model differences and rounding error.

7. Expenses from continuous facility stays of two or more years are grouped with facility, and those from stays where admission and discharge are in same calendar year are grouped with institution.

8. Excludes inpatient and facility/institution medications.

9. Confidence interval unreliable due to small point estimate.

$65-74, \$ 12,451$ for $75-84$, and $\$ 18,689$ for $85+$ year olds. This increase in end-of-life non-Medicare costs with increasing age at death was statistically significant as indicated by nonoverlap of 95 percent confidence intervals. 
Medicare expenditures constituted 63 percent $(95$ percent Confidence Interval [CI]: 60-66 percent) of terminal year expenditures and HMOs (both Medicare and non-Medicare combined) paid 1.7 percent (95 percent CI: 1.1-2.8 percent) of terminal year expenditures. Inpatient care, facility, and medical provider expenditures were the leading last-year-of-life expenditures with means of $\$ 15,461, \$ 8,879$, and $\$ 6,377$, respectively.

The mean total annual expenditures for nonterminal years were $\$ 7,365$, including \$3,775 Medicare and \$3,590 non-Medicare expenses. Medicare expenses constituted 51 percent (95 percent CI: $47-56$ percent) of nonterminal year expenditures and HMOs (both Medicare and non-Medicare combined) paid 3.6 percent (95 percent CI: 2.4-5.2 percent) of nonterminal year expenses. Mean nonterminal year Medicare expenses increased with age; $\$ 3,247$ for $65-74, \$ 4,153$ for $75-84$, and $\$ 5,052$ for $85+$ year olds. The increase in mean non-Medicare expenses with age of subject for nonterminal years was even greater; $\$ 2,472$ for $65-74, \$ 3,679$ for $75-84$, and $\$ 8,843$ for $85+$ years. Both trends were statistically meaningful with nonoverlapping 95 percent confidence intervals. Inpatient care and facilities were the leading expenditures for nonterminal years of life with annual means of $\$ 2,040$ and $\$ 1,497$, respectively.

The estimates for Medicaid and supplemental insurance expenses in Table 2 compare mean expenditures on a population basis rather than being restricted to eligible and enrolled persons. The overall mean Medicaid expenditures in Table 2 of $\$ 5,051$ per person during the last 12 months of life includes persons not enrolled in Medicaid (and thus with $\$ 0$ in Medicaid expenditures). Because about 32 percent of elderly were enrolled in Medicaid during their last year of life, an average of $\$ 15,784(=\$ 5,051 / 0.32)$ Medicaid dollars were spent on terminal year care for each Medicaid eligible decedent. Similarly, Medicaid spends on average $\$ 849$ per person during nonterminal years. Because about 13 percent of persons not in their terminal year of life were enrolled in Medicaid, this corresponds to an average of $\$ 6,531$ ( = \$849/0.13) for nonterminal years for each Medicaid eligible person.

Table 3 presents estimated national annual expenditures (1996 dollars) for Medicare beneficiaries 65 years of age and older based on the average 1992-1996 beneficiary population size. The amounts, broken down by payer and service category, include: expenditures for terminal years of life (column 2), for nonterminal years of life (column 3); percent of total expenditures spent on terminal years (column 4), and the expenditure ratio (mean terminal year of life/mean annual nonterminal year of life) (column 5). 
Table 3: Annual National Expenditures of Decedents and Nondecedents and Person-Year Adjusted Expenditures from 1992-1996 ${ }^{1}$

\begin{tabular}{|c|c|c|c|c|}
\hline & \multicolumn{2}{|c|}{$\begin{array}{c}\text { Annual Expenditures (Millions of } \\
\text { Dollars) }\end{array}$} & \multirow{2}{*}{$\begin{array}{c}\text { Percent Spent } \\
\text { on Decedents } \\
(95 \% \text { CI) }\end{array}$} & \multirow{2}{*}{$\begin{array}{c}\text { Decendent/ } \\
\text { Nondecedent } \\
\text { Ratio of Mean } \\
\text { Expenditures per } \\
\text { Person } \\
\text { Year (95\% CI) }\end{array}$} \\
\hline & $\begin{array}{c}\text { Decedents } \\
N=1,676,095\end{array}$ & $\begin{array}{c}\text { Nondecedents } \\
N=30,593,741\end{array}$ & & \\
\hline All Expenses ${ }^{2}$ & $\$ 62,989$ & $\$ 219,082$ & $22 \%(20 \%-24 \%)$ & $4.98(4.48-5.53)$ \\
\hline \multicolumn{5}{|l|}{ Expenses by Payer } \\
\hline Medicare & $\$ 39,789$ & $\$ 112,310$ & $26 \%(23 \%-30 \%)$ & $6.29(5.20-7.61)$ \\
\hline Non-Medicare & $\$ 23,200$ & $\$ 106,772$ & $18 \%(16 \%-20 \%)$ & $3.86(3.42-4.35)$ \\
\hline \multicolumn{5}{|l|}{ (Major Payers) } \\
\hline Out-of-pocket & $\$ 8,734$ & $\$ 48,802$ & $15 \%(14 \%-17 \%)$ & $3.18(2.81-3.60)$ \\
\hline Medicaid & $\$ 8,466$ & $\$ 25,277$ & $25 \%(21 \%-30 \%)$ & $5.95(4.61-7.67)$ \\
\hline $\begin{array}{l}\text { Supplemental } \\
\text { Insurance }^{3}\end{array}$ & $\$ 3,515$ & $\$ 21,773$ & $14 \%(10 \%-19 \%)$ & $2.87(2.06-3.99)$ \\
\hline $\mathrm{HMO}^{4}$ & $\$ 1,075$ & $\$ 7,855$ & $12 \%(6.7 \%-22 \%)$ & $2.43(1.24-4.75)$ \\
\hline \multicolumn{5}{|c|}{ Expenses by Service $^{6}$} \\
\hline Inpatient care & $\$ 25,927$ & $\$ 60,756$ & $30 \%(26 \%-34 \%)$ & $7.58(6.29-9.12)$ \\
\hline $\begin{array}{l}\text { Outpatient } \\
\text { hospital }\end{array}$ & $\$ 3,094$ & $\$ 18,083$ & $15 \%(11 \%-19 \%)$ & $3.04(2.28-4.04)$ \\
\hline Medical provider & $\$ 10,688$ & $\$ 55,084$ & $16 \%(15 \%-18 \%)$ & $3.44(3.03-3.91)$ \\
\hline Facility $^{5}$ & $\$ 14,882$ & $\$ 44,551$ & $25 \%(21 \%-29 \%)$ & $5.93(4.84-7.26)$ \\
\hline Institution $^{5}$ & $\$ 3,733$ & $\$ 4,983$ & $43 \%(34 \%-53 \%)$ & $13.23(9.10-19.43)$ \\
\hline Prescription drugs & $\$ 1,094$ & $\$ 1,767$ & $5.8 \%(5.2 \%-6.5 \%)$ & $1.10(0.98-1.23)$ \\
\hline Home health & $\$ 3,197$ & $\$ 11,082$ & $22 \%(18 \%-27 \%)$ & $5.12(4.02-6.52)$ \\
\hline Dental & $\$ 156$ & $\$ 6,185$ & $2.5 \%(1.4 \%-4.2 \%)$ & $0.45(0.26-0.78)$ \\
\hline Hospice & $\$ 1,232$ & $\$ 179$ & $87 \%(59 \%-\sim 100 \%)$ & $122.35^{7}$ \\
\hline
\end{tabular}

1. Medicare beneficiaries 65 years of age and older; year 1992-1995 expenditures adjusted to 1996 dollars.

2. Adjusted to be consistent with sum of Medicare and non-Medicare expenses.

3. Includes private and employer-purchased coverage.

4. Includes Medicare and non-Medicare HMO.

5. Expenses from continuous facility stays of two or more years are grouped with facility, and those from stays where admission and discharge are in same calendar year are grouped with institution.

6. Totals for services in columns 2 and 3 are slightly different than the amount for all expenses in those columns due to model differences.

7. Confidence interval unreliable because denominator is to close to zero.

Of the estimated $\$ 282$ billion total annual medical expenses for persons 65 and older, 22 percent (95 percent CI: 20-24 percent) were spent during terminal years of life. A higher portion of Medicare expenses, 26 percent 
(95 percent CI: 23-30 percent), than non-Medicare expenses, 18 percent (95 percent CI: $16-20$ percent) went to terminal years of life. When payer is considered, the expenditure ratio (mean terminal year of life/mean annual nonterminal year of life) ranged from 6.3 for Medicare expenses to less than 3 for supplemental insurance and HMO expenses. Nearly the same proportion of Medicaid payments, 25 percent (95 percent CI: 21-30 percent) as Medicare payments went to terminal years of life. Among services, an estimated 87 percent of hospice, 43 percent of institution, 30 percent of inpatient care, and 25 percent of facility expenditures went to terminal years of life.

Table 4 presents estimated proportions of terminal-year-of-life expenditures spent in the final 1,3, and 6 months of life and Figure 1 plots mean cumulative terminal year of life Medicare, all non-Medicare, and Medicaid expenses backward from death over the last 1-12 months of life. For example, the diamonds at 1,3 , and 6 months on the Medicare line of Figure 1 signify that mean Medicare expenses (in 1996 dollars) during the last 1, 3, and 6 months of life were $\$ 9,006, \$ 13,383$, and $\$ 17,672$, respectively. Medicare expenses (in 1996 dollars) during the last 1,3 , and 6 months of life were $\$ 9,006, \$ 13,383$, and $\$ 17,672$, respectively. Overall, about 30 percent, 51 percent, and 71 percent respectively of all terminal year expenses occurred during the last 1,3 , and 6 months of life. These proportions were higher with younger age at death. For terminal year Medicare expenses, 38 percent, 56 percent, and 74 percent were in the last 1,3 , and 6 months of life respectively compared to only 18 percent, 36 percent, and 59 percent for non-Medicare expenses. These differences were significant as indicated by nonoverlap of the 95 percent confidence intervals for the true values. Medicaid expenditures (mostly for long-term care facility services) were distributed quite evenly throughout the terminal year of life with close to $1 / 12,3 / 12$, and $6 / 12$ respectively being paid during the last 1, 3, and 6 months of life. Among services, 51 percent of terminal year inpatient care and 36 percent of hospice care payments occurred in the last month of life.

\section{DISCUSSION}

This is the first nationwide analysis of last-year-of-life medical expenditures to include non-Medicare expenses. From 1992-1996, about 22 percent of all medical expenditures for the elderly went to the last year of life. Mean yearly medical expenditures were $\$ 37,581$ for the terminal year of life and $\$ 7,365$ for other years. Medicare paid a larger portion of terminal-year (63 percent) than 
Table 4: Distribution of 1992-1996 Health Care Expenditures Made during Last Year of Life ${ }^{1}$

\begin{tabular}{|c|c|c|c|}
\hline & \multicolumn{3}{|c|}{ Portion of Last Year Expenses in Time Period } \\
\hline & $\begin{array}{l}\text { Last Month } \\
\text { of Life }\end{array}$ & $\begin{array}{c}\text { Last Three Months } \\
\text { of Life }\end{array}$ & $\begin{array}{c}\text { Last Six Months } \\
\text { of Life }\end{array}$ \\
\hline Total & $30 \%(26 \%-35 \%)$ & $51 \%(48 \%-54 \%)$ & $71 \%(70 \%-73 \%)$ \\
\hline \multicolumn{4}{|l|}{$(\text { By Age Group })^{2}$} \\
\hline $65-74$ & $39 \%(28 \%-54 \%)$ & $57 \%(49 \%-67 \%)$ & $75 \%(70 \%-80 \%)$ \\
\hline $75-84$ & $30 \%(24 \%-37 \%)$ & $50 \%(46 \%-55 \%)$ & $71 \%(68 \%-74 \%)$ \\
\hline $85+$ & $24 \%(20 \%-28 \%)$ & $46 \%(43 \%-49 \%)$ & $69 \%(67 \%-70 \%)$ \\
\hline \multicolumn{4}{|l|}{ Expenses by Payer } \\
\hline Medicare & $38 \%(32 \%-45 \%)$ & $56 \%(52 \%-61 \%)$ & $74 \%(72 \%-77 \%)$ \\
\hline Non-Medicare & $18 \%(14 \%-22 \%)$ & $36 \%(32 \%-41 \%)$ & $59 \%(56 \%-63 \%)$ \\
\hline \multicolumn{4}{|l|}{ (Major Payers) $^{2}$} \\
\hline Out-of-pocket & $19 \%(14 \%-25 \%)$ & $43 \%(40 \%-47 \%)$ & $67 \%(65 \%-69 \%)$ \\
\hline Medicaid & $7.2 \%(3.8 \%-14 \%)$ & $24 \%(21 \%-28 \%)$ & $49 \%(47 \%-52 \%)$ \\
\hline $\begin{array}{l}\text { Supplemental } \\
\text { insurance }\end{array}$ & $30 \%(21 \%-42 \%)$ & $51 \%(44 \%-58 \%)$ & $71 \%(67 \%-75 \%)$ \\
\hline \multicolumn{4}{|c|}{ Expenses by Service } \\
\hline Inpatient care & $51 \%(42 \%-62 \%)$ & $66 \%(59 \%-73 \%)$ & $80 \%(76 \%-84 \%)$ \\
\hline Outpatient hospital & $16 \%(10 \%-24 \%)$ & $31 \%(26 \%-37 \%)$ & $54 \%(50 \%-58 \%)$ \\
\hline Medical provider & $25 \%(21 \%-30 \%)$ & $48 \%(44 \%-51 \%)$ & $69 \%(67 \%-71 \%)$ \\
\hline Facility $^{4}$ & $9.9 \%(6.9 \%-14 \%)$ & $26 \%(24 \%-29 \%)$ & $51 \%(50 \%-53 \%)$ \\
\hline Institution $^{4}$ & $20 \%(13 \%-30 \%)$ & $34 \%(28 \%-42 \%)$ & $56 \%(52 \%-61 \%)$ \\
\hline Home health & $11 \%(5.8 \%-19 \%)$ & $37 \%(33 \%-42 \%)$ & $63 \%(61 \%-66 \%)$ \\
\hline Hospice & $36 \%(22 \%-57 \%)$ & $55 \%(44 \%-68 \%)$ & $74 \%(67 \%-81 \%)$ \\
\hline Dental & $\sim 0.0 \%{ }^{5}$ & $18 \%(9.9 \%-31 \%)$ & $45 \%(38 \%-52 \%)$ \\
\hline Prescription drugs ${ }^{6}$ & $9.2 \%(6.1 \%-14 \%)$ & $26 \%(23 \%-29 \%)$ & $50 \%(48 \%-53 \%)$ \\
\hline
\end{tabular}

1. Medicare beneficiaries 65 years of age and older; year 1992-1995 expenditures adjusted to 1996 dollars.

2. Age on January 1 of last calendar year of life.

3. Includes private and employer-purchased coverage.

4. Expenses from continuous facility stays of two or more years are grouped with facility, and those from stays where admission and discharge are in same calendar year are grouped with institution.

5. Confidence interval unreliable due to logarithmic transformation of numbers close to zero.

6. Excludes inpatient medication.

nonterminal-year-of-life (51 percent) expenditures. But Medicaid, out-ofpocket, and private insurance expenditures were also substantially higher during the last year of life, with means of $\$ 5,051, \$ 5,211$, and $\$ 2,097$ respectively, compared to $\$ 849, \$ 1,641$, and $\$ 731$ for nonterminal years. 
Figure 1: $\quad$ Mean Cumulative Last-Year-of-Life Medical Expenses (1996 Dollars) by Number of Months Backward from Death for 1992-1996 Medicare Beneficiaries 65 Years of Age and Older.

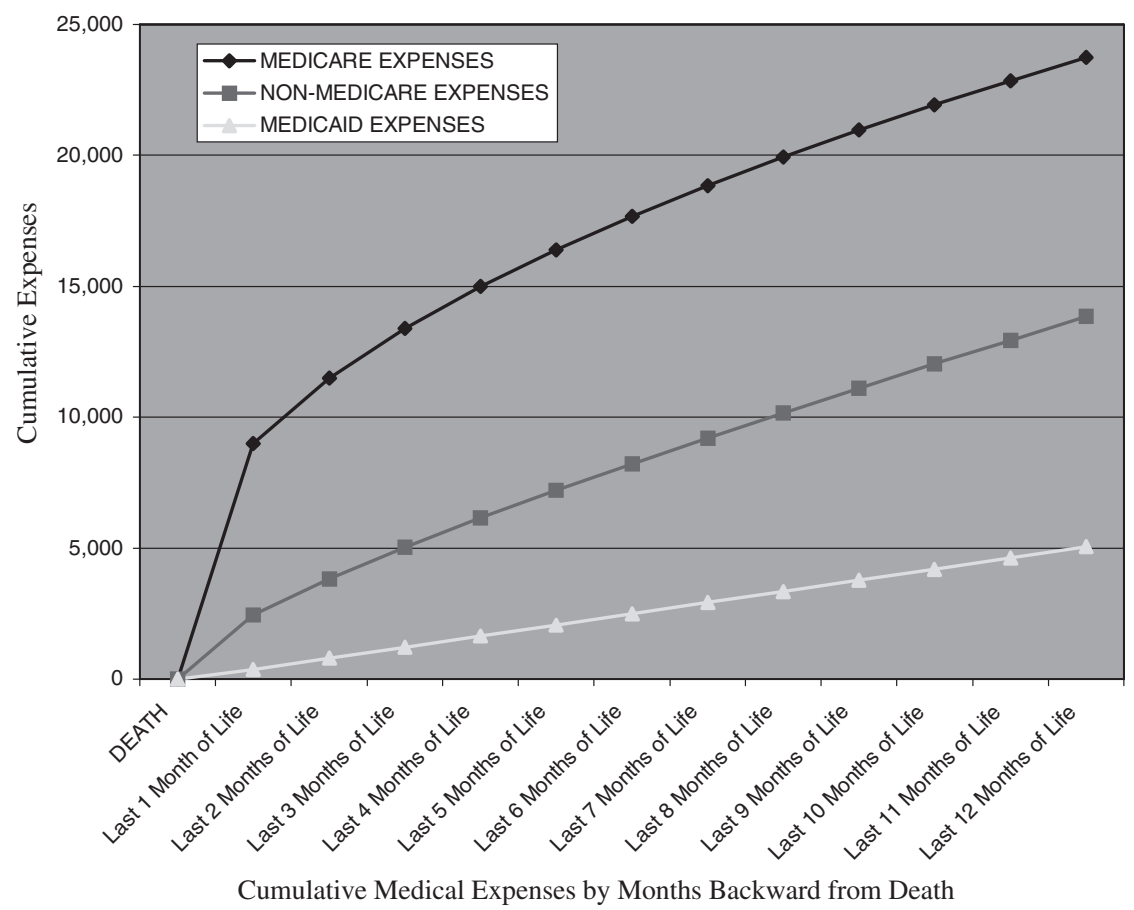

The mean out-of-pocket expenditures of $\$ 5,211$ for the last 12 months of life would be a substantial burden for most families; efforts to reduce out-ofpocket expenditures should consider terminally ill patients. But mean outpatient prescription drug costs declined from $\$ 1,770$ annually to $\$ 1,094$ during the last year of life, perhaps reflecting greater third party coverage of drugs administered during inpatient stays or in hospice care. While prescription drugs are an important overall out-of-pocket cost burden for older people (Crystal et al. 2000), they may not be a central element in out-ofpocket expenditures near the end of life.

Higher annual inpatient health expenditures for the terminal year, at $\$ 15,461$ versus $\$ 2,040$ for other years, were a major contributor to increased terminal year expenditures. Since 51 percent of terminal year inpatient care expenses occurred in the last month of life, one might think that substantial 
savings could accrue by curtailing such expenditures for "hopelessly ill" persons. But even if a person's death could be accurately predicted one month in advance and 50 percent of inpatient medical expenses could be eliminated, this would only reduce average terminal year inpatient costs by $\$ 3,900$ (about 10 percent of average medical expenditures in the last year of life).

The second-largest service contribution to higher terminal year expenditures was facility expenses, with an annual mean of $\$ 8,879$ during the last year of life versus $\$ 1,497$ for other time periods. This reflects higher death rates among persons already in facilities rather than facility expenditures rising due to acute end-of-life conditions, as average annual facility cost for persons with facility expenses were $\$ 27,747$ during the last year of life versus $\$ 24,950$ during other time periods. This suggests that efforts to reduce facility expenses should thus be equally directed to all facility dwellers rather than just the terminally ill.

The mean total amount of medical expenditures in the last year of life from 1992-1996 did not vary by age of death. Higher last-year-of-life Medicare expenses (going largely to hospitals) among those under the age of 85 ( $\sim \$ 26,000-\$ 28,000$ versus $\sim \$ 18,000$ for those 85 and older) were offset by lower last-year-of-life non-Medicare costs (going largely to facilities), which averaged $\$ 9,211$ for those $65-74$ years versus $\$ 18,689$ for those $85+$. Similar patterns were seen in patients of a Palo Alto clinic (Scitovsky 1984) and nationwide (Spillman and Lubitz 2000).

Total national medical expenditures for persons in their last year of life could increase significantly in the future as Americans age (cf., Hollman et al. 2000). This is particularly true for end-of-life non-Medicare expenditures that increase with age of death, as the elderly population is shifting to older age groups. But total national end-of-life Medicare expenditures may not rise as much since average end-of-life Medicare expenditures decline with older age at death (Lubitz, Beebe, and Baker 1995).

Our estimated portion of Medicare expenses spent on the last year of life in 1992-1996 (26 percent) was statistically in the range of 27-31 percent; the proportions of Medicare expenditures found spent on the last year of life between 1976 and 1988 (Lubitz and Riley 1993). These and similar findings (Garber, MaCurdy, and McClellan 1999; Hogan et al. 2001) suggest the proportion of Medicare spending going to end-of-life care is not increasing despite the growth of new critical-care technologies that have been accused of extending the dying process at considerable cost (Callahan 1987). Current efforts to reduce end-of-life expenditures may be too small to measure in this study, particularly if countered by upward trends. For example, hospice care 
may reduce last-year-of-life expenditures an average of $\$ 2,737$ per person (Emanuel 1996). With 19 percent using hospices in their last year of life (Hogan et al. 2001), this translates into a mean reduction of $\$ 520$ (only $\sim 1.5$ percent of average end-of-life costs) per person.

Some limitations of this analysis should be noted. Many MCBS expenditures are based on self-reports from patients and proxies. While Medicare reports are confirmed by claims, non-Medicare expenses cannot be equivalently validated. However, approaches used to validate these data are very effective (Eppig and Chulis 1997). As facility expenditures are reported directly by billing office workers, Medicaid expenditures should be especially valid. The polynomial models used here would theoretically yield invalid results if end-of-life costs systematically increase or decrease with calendar month of death. However, sensitivity analysis showed that the model was robust to violations of this pattern (data not shown). The number of decedents in our data set $(3,200)$ was large enough to resist the effects of single outliers with huge expenditures. For example, excluding the five decedents with the largest total medical expenditures only reduced our end-of-life expenditure estimates by 3 percent.

Our estimated Medicare expenditures for the last 12 months of life are consistent with 12 month end-of-life Medicare expenses observed by Garber et al. (1999) in the 20 percent Medicare sample and Hogan et al. (2001) in a 0.1 percent sample of decedents. Our estimated 1992-1996 mean Medicare expenses during the last year of life, converted from 1996 to 1995 dollars, were $\$ 22,967$ compared to $\sim \$ 23,000$ in the 20 percent Medicare sample (Garber, MaCurdy, and McClellan 1999). The mean last-year-of-life Medicare expenditures of $\$ 26,300$ (in 1997 inflation adjusted dollars) reported by Hogan et al. (2001) for a 1993-1998, 0.1 percent sample of elderly decedents is similar to our estimated mean from 1992-1996 of \$23,739 in 1996 dollars considering time period differences and inflation from 1996 to 1997.

In summary, end-of-life Medicare expenses grew in the early 1990s at about the same rate as did other Medicare expenses. Non-Medicare expenditures from 1992-1996 increased at the end of life, but to a lesser degree than did Medicare expenses. Additional non-Medicare expenditures near the end of life are directed toward facility-based management of chronic conditions preceding death rather than to acute terminal conditions per se. Out-of-pocket expenditures near the end of life are a great burden for many families of decedents and these expenditures should be reduced. But costs for outpatient prescription drugs are less for the terminally ill than for other elderly. As the elderly population ages, (inflation adjusted) average total 
end-of-life medical expenses will probably change little, but the portion paid by non-Medicare sources (supporting chronic and custodial care) will likely rise. Policies promoting improved allocation of resources for care near the end of life are likely to be least effective for non-Medicare expenditures, suggesting efforts to contain these expenditures should not focus on those near the end of life.

\section{REFERENCES}

Barnato, A. E., A. M. Garber, C. R. Kagay, and M. C. McClellan. 1999. "Trends in the Use of Intensive Procedures at the End of Life." In Frontiers in Health Policy Research, Vol. 2, edited by A. Garber, Cambridge, MA: MIT Press.

Callahan, D. 1987. Setting Limits: Medical Goals in an Aging Society. New York: Simon and Schuster.

Crystal, S., J. Harman, U. Sambamoorthi, R. Johnson, and R. Kumar. 2000. "Out of Pocket Health Care Costs among Older Americans.” Journal of Gerontology: Social Sciences 55B (1): S51-S62.

Cutler, D. M., and M. C. McClellan. 2001. "Is Technical Change Worth It?" Health Affairs 20 (5): 11-29.

Emanuel, E. J. 1996. “Cost Savings at the End of Life. What Do the Data Show? [see comments]. Journal of the American Medical Association 275 (24): 1907-14.

Emanuel, E. J., and L. L. Emanuel. 1994. "The Economics of Dying. The Illusion of Cost Savings at the End of Life." New England Journal of Medicine 330 (8): 540-4.

Eppig, F., and G. S. Chulis. 1997. "Matching MCBS and Medicare Data: The Best of Both Worlds." Health Care Financing Review 18 (3): 211-29.

Garber, A. M., T. MaCurdy, and M. McClellan. 1999. "Medical Care at the End of Life: Diseases, Treatment Patterns and Costs." In Frontiers in Health Policy Research, Vol. 2, edited by A. Garber, Cambridge, MA: MIT Press.

Gaumer, G. L., and J. Stavins. 1992. "Medicare Use in the Last Ninety Days of Life." Health 26 (6): 725-42.

Hogan, C., J. Lunney, J. Gabel, and J. Lynn. 2001. "Medicare Beneficiaries Cost of Care in the Last Year of Life." Health Affairs 20 (4): 188-95.

Hollman, F. W., T. J. Mulder, and J. E. Kallan. 2000. "Population Division U.S. Census Bureau. Methodology and Assumptions for Population Projections of the United States: 1999-2100." Working paper no. 38.

Kramer, A. M. 1995. "Health Care for Elderly Persons-Myths and Realities." [editorial; comment] New England Journal of Medicine 332 (15): 1027-9.

Lehman, E. 1997. Theory of Point Estimation. New York: Springer.

Lubitz, J., J. Beebe, and C. Baker. 1995. "Longevity and Medicare Expenditures." New England Journal of Medicine 332 (15): 1027-9.

Lubitz, J. D., and G. F. Riley. 1993. "Trends in Medicare Payments in the Last Year of Life." New England Journal of Medicine 328 (15): 1092-6. 
McCall, N. 1984. "Utilization and Expenditures of Medicare Services by Beneficiaries in Their Last Year of Life." Medical Care 22 (4): 329-42.

Olin, G. L., H. Liu, and B. Merriman. 1996. Health $\&$ Health Care of the Medicare Population Data from the 1995 Medicare Beneficiary Survey. Rockville, MD: Westat.

Riley, G., J. Lubitz, R. Prihoda, and E. Rabey. 1987. "The Use and Expenditures of Medicare Services by Cause of Death." Inquiry 24 (3): 233-44.

Scitovsky, A.A. 1984. "The High Cost of Dying: What Do the Data Show?" Milbank $62(4):$ 591-608.

. 1988. "Medical Care in the Last Twelve Months of Life: The Relation between Age, Functional Status, and Medical Care Expenditures." Milbank 66 (4): 640-60.

. 1994. "The High Cost of Dying Revisited." Milbank 72 (4): 561-91.

Shah, B. V., B. G. Barnwell, and G. S. Bieler. 1996. SUDAAN: Software for the Statistical Analysis of Correlated Data. Release 7.0, user's manual. Research Triangle Park, NC: Research Triangle Institute.

Spillman, B. C., and J. Lubitz. 2000. "The Effect of Longevity on Spending for Acute and Long-term Care." New England Journal of Medicine 342 (19): 1409-15.

Temkin-Greener, H., M. R. Meiners, E. A. Petty, and J. S. Szydlowski. 1992. "The Use and Cost of Health Services Prior to Death: A Comparison of the Medicare-only and the Medicare-Medicaid Elderly Populations." Milbank 70 (4): 679-701.

Waldo, D. R., S. T. Sonnefeld, R. D. McKusick, and R. H. Arnett III. 1989. "Health Expenditures by Age Group, 1977 and 1987." Health Care Finance Review 10 (4): $111-20$. 